\title{
A cross sectional study on prescription pattern of drugs in upper respiratory tract infections in a tertiary care hospital
}

\author{
Divya Bade ${ }^{1}$, Shivashankaramurthy K. G. ${ }^{2 *}$, Kiran L. J. ${ }^{2}$, Raghuprasada M. S. ${ }^{2}$, \\ Harishkumar V. S. ${ }^{2}$, Pradeep A. N. ${ }^{2}$
}

\author{
${ }^{1}$ Medical Advisor, TCS Olympus, Thane, Mumbai, Maharashtra, India \\ ${ }^{2}$ Department of Pharmacology, S.S. Institute of Medical Sciences and Research Centre, Davangere, Karnataka, India
}

Received: 07 December 2019

Revised: 08 January 2020

Accepted: 13 January 2020

\section{*Correspondence:}

Dr. Shivashankaramurthy K. G.,

Email: drshivu2012@gmail.com

Copyright: (C) the author(s), publisher and licensee Medip Academy. This is an open-access article distributed under the terms of the Creative Commons Attribution Non-Commercial License, which permits unrestricted non-commercial use, distribution, and reproduction in any medium, provided the original work is properly cited.

\begin{abstract}
Background: Upper respiratory tract infections are one of the leading causes of hospital visits worldwide. Judicious use of antibiotics is challenging for upper respiratory tract infections (URTIs) in developing countries like India. This leads to inappropriate use of antibiotics causing many dreaded conditions like antibacterial resistance among other things. Hence rational use of drugs, mainly antibacterial, is a priority to reduce the burden of treatment failure. The objective of this study is to study the prescribing patterns and rationality of drugs prescribed in the management of URTIs.

Methods: This was a cross-sectional study. Data was collected from records of 300 outpatients clinically diagnosed as URTIs from SSIMS and RC Hospital, Davangere between January 2015 and June 2016. The prescribing patterns, approval status and listing of drugs in World Health Organization (WHO) essential medicines list/ National List of Essential Medicines (NLEM) were analysed. The data was presented as percentages, mean and standard deviations.

Results: A total of 300 cases were studied. Among these, acute pharyngitis (29\%) and acute sinusitis (26\%) are the most common infections. Of the 300 cases studied, 283 (94.3\%) were prescribed antimicrobials. Of the total 740 medications prescribed, $393(53.1 \%)$ were fixed-dose combinations (FDCs). A total of 724 medications $(97.8 \%)$ were approved by Drugs Controller General of India and 248 (33.5\%) by Food and Drug Administration. Only 5.8\% of the prescribed drugs have been listed in WHO's and NLEM. The most common class of antibacterials prescribed was Beta-lactams.

Conclusions: Oral formulations were preferred over parenteral formulations and FDCs were preferred over single drug formulations. Beta-lactams comprised the major class of antibacterial prescribed.
\end{abstract}

Keywords: Prescribing patterns, Upper respiratory tract infections, Antimicrobials

\section{INTRODUCTION}

Respiratory tract infections are among the most common causes of morbidity in the community worldwide. ${ }^{1}$ In a recent report, in India during the year 2011, about 26.3 million cases of acute respiratory infections were reported which gives an incidence rate of about 2179 cases per lakh population. ${ }^{2}$ Largely because of the higher incidence rate, upper respiratory tract infections (URTIs) impose a greater burden than most of the other clinical conditions. Viruses are the causal pathogens in most upper respiratory infection cases, with fewer than $10 \%$ of the cases caused by bacteria. ${ }^{3}$ Rhinovirus is the most common cause of URTI. Other common causes include influenza virus, parainfluenza virus, coronavirus and adenovirus. Respiratory syncytial virus also accounts for 
a small percentage of cases each year. ${ }^{4}$ Differentiating patients with primary viral infection from those with primary bacterial infection is difficult. Signs and symptoms of bacterial and viral URTIs are, in fact, indistinguishable. Antibiotics may be warranted in some cases, but many a time they are overused. The prevalence of use of antibiotics in India varies from $24 \%$ to $67 \% .^{4}$ This might lead to increased cost, increased incidence of side effects due to antibiotics themselves and above all, antibiotic resistance. Inappropriate use of antibiotics thus is a major public health concern since it is associated with augmented antibiotic resistance in the population. ${ }^{5}$ Routine and rapid diagnostic testing is neither available nor practical for most cases they are diagnosed largely on clinical grounds. Thus, judicious use of drugs including antibiotics in this setting is challenging. ${ }^{6}$

The other medicines prescribed for the URTIs include anti-histaminic drugs, decongestants, non-steroidal antiinflammatory drugs (NSAIDs) etc. The drug utilization studies recognize the problems that stem from drug use in healthcare delivery system. They highlight the current methods to the rational use of medicines. ${ }^{7}$ The present study is intended to explore the prescription pattern of drugs.

\section{Objectives}

To study the prescription pattern of drugs used in URTI patients attending outpatient department (OPD) in the department of ENT and to describe whether the medications prescribed for URTI are approved by the drug regulatory bodies.

\section{METHODS}

\section{Study place}

The study was done at S S Institute of Medical Sciences and Research Centre Hospital, Davangere, Karnataka.

Study design: This was a cross-sectional study.

\section{Source of data}

The data was taken from the adult patients clinically diagnosed with URTIs attending OPD of E.N.T Department, S.S. Institute of Medical Sciences and Research Centre Hospital, Davangere, Karnataka, from January 2015 to May 2016. Prior permission of the higher authorities and Institutional Ethics Committee clearance was obtained before conducting the study.

Supportive findings in routine or special investigations were taken into account for diagnosis by the clinician. To evaluate the drug prescribing pattern, a predesigned proforma containing relevant details such as outpatient number, demographics (age, sex), dates, duration of treatment, clinical diagnosis were noted. All the drugs prescribed (generic/brand name) with respect to dosage, route, frequency and duration of administration were recorded as per the proforma.

\section{Selection criteria of the patients}

\section{Inclusion criteria}

All adult patients diagnosed with acute and chronic URTI (OPD). Patients with age 18 years and above. And both the sex are included.

\section{Exclusion criteria}

Patients with lower respiratory tract infections. Patients with associated co-morbid conditions. Pregnant woman and smokers. Patients who are not willing to give written informed consent.

\section{Analysis of data}

The data was subjected to descriptive analysis using Microsoft Excel version 2010.

Utilization of different classes of drugs as well as individual drugs were analysed and presented as percentage.

\section{RESULTS}

\section{Demographic data}

300 patients who attended ENT OPD with a clinical diagnosis of URTIs were randomly selected and included in the study.

Sex

Out of 300 patients, $152(50.66 \%)$ were female patients and $148(49.33 \%)$ were males, with female to male ratio of 1.02:1.

\section{Age}

The maximum numbers of patients are seen in between the ages 20-40 years, whereas the least number of cases are from ages 60 years and above.

Table 1: Age distribution.

\begin{tabular}{|ll|}
\hline Age in years & $\mathbf{N}(\%)$ \\
\hline$<\mathbf{2 0}$ & $32(10.66)$ \\
\hline $\mathbf{2 0 - 3 9}$ & $154(51.34)$ \\
\hline $\mathbf{4 0 - 5 9}$ & $97(32.3)$ \\
\hline $\mathbf{6 0}$ and above & $17(5.67)$ \\
\hline
\end{tabular}

\section{Diagnosis}

Out of the 300 cases, acute pharyngitis (29\%) and acute sinusitis $(28 \%)$ are the most commonly diagnosed URTIs. 


\section{Prescription data}

A total of 740 drugs were prescribed in 300 patients, of which 283 were antibacterial. 457 adjuvant drugs were prescribed of which 281 are NSAIDs and their fixed-dose combinations (FDCs), 123 were mucolytics, 44 were proton-pump inhibitors (PPIs) and their combinations, 9 were antihistamines.

\section{Antibiotics prescribed}

Cefpodoxime as a single drug formulation is the most commonly prescribed antibiotic and it is the only single drug formulation in antibacterial. Ciprofloxacin and tinidaxole FDC is the least commonly prescribed antibiotic, whereas amoxicillin and clavulnic acid is the commonly prescribed FDC antibacterial. Of all the antibiotics prescribed, single drug formulations constitute $72.08 \%$ whereas FDCs make up to $27.91 \%$.

Table 2: Antibiotics prescribed.

\begin{tabular}{|ll|}
\hline Drug prescribed & N (\%) \\
\hline Cefpodoxime & $204(74)$ \\
\hline Cefpodoxime and clavulanic acid & $30(11)$ \\
\hline Amoxicillin and clavulanic acid & $33(11.67)$ \\
\hline Ciprofloxacin and tinidazole & $16(5.6)$ \\
\hline
\end{tabular}

\section{Adjuvant drugs prescribed}

Of the adjuvant drugs prescribed, diclofenac and serratiopeptidase containing FDC is the most commonly prescribed $(33.04 \%)$. Of the adjuvant drugs prescribed, FDCs are more common $(68.7 \%)$ compared to single drug formulations $(31.3 \%)$.

Of the total prescriptions FDCs $(53.1 \%)$ and single drug formulations $(46.9 \%)$ are prescribed almost in equal numbers. $97.8 \%$ of the prescribed medications are approved by Drugs Controller General of India (DCGI) and $33.5 \%$ by FDA. Only $5.8 \%$ of the total prescribed drugs are listed in both WHOs and national list of essential medicines.

Table 3: Adjuvant drugs prescribed.

\begin{tabular}{|ll|}
\hline Drug prescribed & N $(\%)$ \\
\hline Aceclofenac and paracetamol & $120(26)$ \\
\hline Diclofenac and serratiopeptidase & $151(33.04)$ \\
\hline Ambroxol & $123(27)$ \\
\hline Paracetamol & $10(2.18)$ \\
\hline Rabeprazole and domperidone & $43(9.4)$ \\
\hline Rabeprazole & $1(0.2)$ \\
\hline Chlorpheniramine & $9(2)$ \\
\hline
\end{tabular}

\section{Drug characteristics}

Only $5.8 \%$ of the prescribed drugs have been listed in WHO's and national essential medicine list. Prescribing diclofenac in the place of aceclofenac and pantoprazole instead of rabeprazole would have been increased this percentage highly.

Table 4: Prescription characteristics $(n=740)$.

\begin{tabular}{|llll|}
\hline S. no. & Particulars & N & $\%$ \\
\hline $\mathbf{1}$ & Single drug formulations & 347 & 46.9 \\
\hline $\mathbf{2}$ & Fixed drug formulations & 393 & 53.10 \\
\hline $\mathbf{3}$ & Drugs approved by DCGI & 724 & 97.8 \\
\hline $\mathbf{4}$ & Drugs approved by FDA & 248 & 33.5 \\
\hline $\mathbf{5}$ & Drugs prescribed listed in WHO essential drug list & 43 & 5.8 \\
\hline $\mathbf{6}$ & Drugs prescribed listed in National essential drug list & 43 & 5.8 \\
\hline $\mathbf{7}$ & Oral route administered & 740 & 100 \\
\hline $\mathbf{8}$ & Drugs prescribed by brands & 740 & 100 \\
\hline
\end{tabular}

Table 5: Drug approval status and listing in WHO/NLEM.

\begin{tabular}{|c|c|c|c|c|c|}
\hline S. no. & Drug & DCGI & FDA & WHO & NLEM \\
\hline 1 & Cefpodoxime & $\mathrm{Y}$ & $\mathrm{Y}$ & $\mathrm{N}$ & $\mathrm{N}$ \\
\hline 2 & Paracetamol & Y & $\mathrm{Y}$ & Y & Y \\
\hline 3 & Ambroxol & $\mathrm{Y}$ & $\mathrm{N}$ & $\mathrm{N}$ & $\mathrm{N}$ \\
\hline 4 & Rabeprazole & $\mathrm{Y}$ & $\mathrm{Y}$ & $\mathrm{N}$ & $\mathrm{N}$ \\
\hline 5 & Amoxicillin and clavulanic acid & $\mathrm{Y}$ & $\mathrm{Y}$ & $\mathrm{Y}$ & Y \\
\hline 6 & Cefpodoxime and clavulanic acid & $\mathrm{Y}$ & $\mathrm{N}$ & $\mathrm{N}$ & $\mathrm{N}$ \\
\hline 7 & Ciprofloxacin and tinidazole & $\mathrm{N}$ & $\mathrm{N}$ & $\mathrm{N}$ & $\mathrm{N}$ \\
\hline 8 & Diclofenac and serratiopeptidase & $\mathrm{Y}$ & $\mathrm{N}$ & $\mathrm{N}$ & $\mathrm{N}$ \\
\hline 9 & Aceclofenac and paracetamol & $\mathrm{Y}$ & $\mathrm{N}$ & $\mathrm{N}$ & $\mathrm{N}$ \\
\hline 10 & Rabeprazole and domperidone & $\mathrm{Y}$ & $\mathrm{N}$ & $\mathrm{N}$ & $\mathrm{N}$ \\
\hline
\end{tabular}


Table 6: Drug characteristics.

\begin{tabular}{|c|c|c|c|c|}
\hline S. no. & Drug & ATC code & Drug class & $\begin{array}{l}\text { No. of } \\
\text { presription }\end{array}$ \\
\hline 1 & Cefpodoxime & J01DD13 & $\begin{array}{l}3^{\text {rd }} \text { generation } \\
\text { cephalosporins }\end{array}$ & 204 \\
\hline 2 & Amoxicillin and clavulanic acid & J01CR02 & $\begin{array}{l}\text { Beta-lactum antimicrobials. } \\
\text { penicillins }\end{array}$ & 33 \\
\hline 3 & Ciprofloxacin and tinidazole & J01RA11 & $\begin{array}{l}\text { Combination of } \\
\text { antimicrobials }\end{array}$ & 16 \\
\hline 4 & Diclofenac and serratiopeptidase & M01AB55 & Diclofenac, combinations & 151 \\
\hline 5 & Aceclofenac and paracetamol & M01AB16 & $\begin{array}{l}\text { Acetic acid derivates and } \\
\text { related substances }\end{array}$ & 120 \\
\hline 6 & Ambroxol & R05CB06 & Mucolytics & 123 \\
\hline 7 & Paracetamol & N02BE01 & $\begin{array}{l}\text { Other analgesics and anti } \\
\text { pyretics }\end{array}$ & 10 \\
\hline 8 & Rabeprazole and domperidone & $\begin{array}{l}\text { A02BC04 } \\
\text { A03FA03 }\end{array}$ & $\begin{array}{l}\text { Proton pump inhibitors } \\
\text { (PPI) and propulsives }\end{array}$ & 43 \\
\hline 9 & Rabeprazole & A02BC04 & PPI & 01 \\
\hline
\end{tabular}

\section{DISCUSSION}

Upper respiratory tract infections are one of the most commonly occurring infections worldwide. ${ }^{1}$ These are the conditions which can occur acutely or as chronic illnesses posing a major burden on the patients. Sinusitis, rhinitis, tonsillitis, pharyngitis, laryngitis and otitis media constitute most of the URTIs. Although majority of the cases are caused by viral organisms, differentiating primary viral and bacterial illnesses is difficult. Also, secondary infection with bacteria is quite common in primary viral infections. Routine investigations to check the causative organism is not practical, especially in countries like India. Hence the diagnosis in majority of the cases is made clinically, thus posing a challenge in the treatment using antibiotics. The adjuvant drugs are also used frequently for symptomatic relief, but they would be the same in both viral and bacterial infections as the symptoms of both conditions would be similar.

300 cases were taken for the study, which were diagnosed to be URTIs, during a period of 2 years, compared to a study by Ghosh et al where 300 prescriptions were taken during a 6 month period and analysed. ${ }^{12}$ A female to male ratio of 1.02:1 was noted, with females comprising $50.67 \%$ and males $49.33 \%$.This is similar to a study by Kancherla et al where females comprised $48 \%$ and males $52 \% .{ }^{13}$ Majority of the patients belonged to the age group of 20 to 39 years $(51.33 \%$ ), compared to the study by Gogoi et al where the majority of the patients $(50 \%)$ belonged to the age group 15 to 35 years. ${ }^{14}$ Of these cases, acute pharyngitis $(29 \%)$ and acute sinusitis (26\%) are the most common infections.

A total of 740 medications were prescribed, out of which $283(38.24 \%)$ were anti-microbials. Other 457 include adjuvant drugs for symptomatic relief such as mucolytics and FDCs of NSAIDs and FDCs of PPIs. The average number of medications per person is 3.46 , whereas in a study by Lokare et al it is 4 drugs per patient. ${ }^{15} 94.3 \%$ of the cases had antibiotic prescriptions. The duration of treatment for majority of the cases is 5 to 7 days.

Out of all the medications, 347 (46.9\%) were single drug formulations and $393(53.1 \%)$ were FDCs. A total of 724 (97.8\%) were approved by DCGI and 248 (33.5\%) by FDA. Around $5 \%$ of the medications prescribed were listed in WHO essential medicine list and NLEM as well. All the medications were prescribed by oral route and all of them were prescribed by their brand name.

Of the anti-microbials, cefpodoxime is the most commonly prescribed $(72 \%)$. Analysis or understanding the local organism resistance patterns might be the reason for this. In the adjuvant drugs NSAID containing FDCs were the most common, diclofenac and serratiopeptidase (33\%), aceclofenac and paracetamol (26\%). Others include mucolytics, ambroxol, (27\%) and FDCs having PPI, rabeprazole and propulsives, domperidone (9.4\%) and anti-histaminic drugs, chlorpheniramine (2\%).

The most common single drug formulation is cefpodoxime $(27.56 \%)$ and the common FDC is diclofenac and serratiopeptidase $(20.4 \%)$. This makes the most common class of antibacterial prescribed be Betalactams (ATC class: J01D and J01C).

All the adjuvant drugs and almost all the antimicrobials were approved by DCGI. The antibacterial which is not approved by DCGI is the FDC of ciprofloxacin and tinidazole. Almost all the single drug formulations were approved by FDA except ambroxol. In the FDCs only amoxicillin and clavulanic acid combination was the approved one. The FDCs that were not approved by FDA include ciprofloxacin and tinidazole, cefpodoxime and clavulanic acid, diclofenac and serratiopeptidase, aceclofenac and paracetamol, rabeprazole and domeperidone. Out of all the medications prescribed, the 
FDC of amoxicillin and clavulanic acid and the single drug paracetamol were the only ones listed in both WHO essential medicines list and NLEM.

The above results indicate that there is still need of more rationalising the use of antimicrobial agents in URTIs. Prescription of a drug or a FDC which is not present in the approved list is really alarming. Such drug utilization studies will be an eye opener towards judicious use of drugs especially antimicrobials.

\section{CONCLUSION}

The present study was conducted to determine the prescription pattern in adults suffering with URTI. Antibacterial, NSAIDs and mucolytic were most common prescribed drugs in URTIs. However, prescribed antibiotics were about $38.24 \%$ of total prescribed drugs. This indicates that there is still need of more rationalising the use of antimicrobials in URTIs. Most commonly prescribed antibiotics were cephalosporins and penicillin group of drugs. Single drug formulations were preferred in antibacterial whereas FDCs were preferred in the adjuvant group of drugs. Some prescribed drugs/FDCs were not included in the WHO recommended list.

\section{Funding: No funding sources}

Conflict of interest: None declared

Ethical approval: The study was approved by the Institutional Ethics Committee

\section{REFERENCES}

1. Kiffer CR, Pignatari AC. Pharmacodynamic evaluation of commonly prescribed oral antibiotics against respiratory bacterial pathogens. BMC Infect Dis. 2011;11:286.

2. Park K. Park's textbook of preventive and social medicine. Chapter 2. Epidemiology of communicable diseases. 22nd edition. Jabalpur: Bhanot Publications; 2013: 158.

3. Fendrick AM, Monto AS, Nightengale B, Sarnes M. The economic burden of Non-Influenza related Viral Respiratory Tract Infection in the United States. Arch Intern Med. 2003;163(4):487-94.

4. Ramachandra K, Sanji N, Somashekar HS, Acharya A, Sagar KJ, Halemani SS. Trends In Prescribing Antimicrobials In An Ent Outpatient Department Of A Tertiary Care Hospital For Upper Respiratory Tract Infections. Int $\mathbf{J}$ Pharmacol Clin Sci. 2012;1(1):15-8.

5. Gjelstad S, Dalen I, Lindbæk M. GPs' antibiotic prescription patterns for respiratory tract infections - still room for improvement: Scand J Prim Health Care. 2009;27(4):208-15.

6. Michael RA, Ralph G, Merle SA. Pharyngitis, sinusitis, otitis and other upper respiratory tract infections. In: Fauci AS, Kasper DL, Longo DL, Braunwald E, Hauser SL, Jameson JL, et al (eds). Harrison's Principles of Internal Medicine. 17thedition. New York, McGraw Hill inc. publications; 2008: 205.

7. Pradhan SC, Shewade DG, Shashindran CH, Bapna JS. Drug utilization studies. National Med J India. 1988;1:185-9.

8. List of Drug Approved for Marketing in India. Available at: http://cdsco.nic.in/listofdrugapproved main.html. Accessed 16 June 2016.

9. Drugs@FDA: FDA Approved Drug Products. Available at: http://www.accessdata.fda.gov/scripts/ cder/drugsatfda/index.cfm. Accessed 16 June 2016.

10. WHO Model List of Essential Medicines. World Health Organization. 2015:1-38. Available at: http://www.who.int/medicines/publications/essential medicines/en/index.html. Accessed 19 June 2016.

11. National List of Essential Medicines of India. 2011:1-123. Available at: http://cdsco.nic.in/National List of Essential Medicine- final copy.pdf. Accessed 19 June 2016.

12. Ghosh A, Das AK, Gure PK, Pati S. An observational study of drug use in upper respiratory tract infection in patients attending ENT outpatient department in a tertiary care hospital in Kolkata. Asian J Pharmaceut Clin Res. 2015;8(4)37-40.

13. Kancherla D, Sai S, Devi G, Sharma S. A study on prescribing pattern of antibiotics in respiratory tract infections in a tertiary care center. Int J Recent Sci Res. 2015;6(6):4558-63.

14. Gogoi S, Saikia PP. A study on prescribing patterns of antibiotics for upper respiratory tract infections by general practitioners in rural areas of Assam. Int $\mathbf{J}$ Scientific Res. 2015;4(5):60-2.

15. Lokare AB, Ramanand JB. Drug utilization pattern in upper respiratory tract infection in outpatient department of government hospital and C.P.R. hospital in Kolhapur. Indian J Basic Appl Med Res. 2016;5(3):95-100.

Cite this article as: Bade D, Shivashankaramurthy KG, Kiran LJ, Raghuprasada MS, Harishkumar VS, Pradeep AN. A cross sectional study on prescription pattern of drugs in upper respiratory tract infections in a tertiary care hospital Int J Basic Clin Pharmacol 2020;9:271-5. 